\title{
Existências lesbianas: por um aporte epistemológico lesbiano preto
}

Jaqueline Gil B. Barreto ${ }^{1}$

Resumo: No contexto do heteropatriarcado, a heteronormatividade está presente. As demais orientações sexuais são consideradas inferiores. Diante disso, pergunta-se: uma mulher negra lesbiana, por não se encaixar nessa heteronorma, pode ser impactada negativamente no que diz respeito à vivência e expressão da sua sexualidade? De que maneira o feminismo negro interseccional pode contribuir para o debate sobres as lesbianidades de mulheres negras? Nessa discussão, uma mulher lesbiana branca pode falar pelas mulheres lesbianas negras? Com base em uma revisão de literatura acerca das epistemologias que tratam do feminismo lesbiano negro interseccional e das lesbianidades de mulheres negras inseridas no contexto do heteropatriarcado, o objetivo do presente artigo teórico é apresentar uma reflexão acerca dessa questão. Nesse sentido, pretende-se contribuir para a construção de um aporte epistemológico lesbiano negro que venha a desestabilizar uma epistemologia ainda predominantemente branca e heteronormativa, em que há um silenciamento histórico sobre a sexualidade da mulher lesbiana negra.

Palavras-chave: Lesbianidades. Heteropatriarcado. Feminismo negro interseccional. Branquitude.

\begin{abstract}
In the context of heteropatriarchy, heteronormativity is present. In this sense, the other sexual orientations are considered inferior. Can a lesbian black woman not fit into this heteronorm be negatively impacted on the experience and expression of her sexuality? How can intersectional black feminism contribute to the debate about black women's lesbianities? In this context of discussion, can a white lesbian woman speak for black lesbian women? From a literature review about the epistemologies that deal with intersectional black lesbian feminism, this theoretical article aims to present a reflection on this issue. Thus, we seek to contribute to the visibility of black lesbian women who are still triple stigmatized because they are women, black and lesbian.
\end{abstract}

Keywords: Lesbianities. Heteropatriarchy. Intersectional black feminism. Whiteness.

\footnotetext{
${ }^{1}$ Doutoranda em Difusão do Conhecimento pela Universidade Federal da Bahia (UFBA). Mestra em Administração pela UFBA. Docente do Instituto Federal da Bahia. E-mail: jaquelinegil_644@hotmail.com.
} 


\section{Introdução}

Ao iniciar este apartado, é indispensável, antes, destacar que, no âmbito macro investigativo, ele se desenvolve na perspectiva da "pesquisadora encarnada em sua corporeidade, cujas marcas de gênero, raça, classe, colonialidade e desejo sexual" (MESSEDER, 2016, p. 2) permeiam a produção do conhecimento científico. Assim, consideram-se as vivências, os olhares e percepções desta que fala para a proposta do trabalho científico, não olvidando os devidos distanciamentos que emergem para a execução dos rigores pautados pela academia.

Lembro-me ainda como foi difícil me sentir segura e confiante o suficiente para romper as barreiras de um "armário" no qual eu nunca quis estar. O termo "armário" refere-se a uma estrutura definidora de opressão, considerado dispositivo de regulação da vida de lesbianas e gays (SEDWICK, 2007). Boa parte da minha existência foi marcada pela presença de um armário, o qual me impossibilitou de viver a sexualidade, feliz e plenamente. Nesse sentido, se para mim, não foi (e não é) fácil vivenciar e expressar a sexualidade, em uma condição de privilégio por ser uma mulher branca, que dirão as mulheres lesbianas negras, haja vista o enfrentamento diário de tantos preconceitos? Pergunto-me, ainda, na condição de mulher branca, posso falar sobre a sexualidade das mulheres lesbianas negras? Como será a vivência e expressão da sexualidade para as mulheres lesbianas negras inseridas no contexto do heteropatriarcado? O que nos dizem sobre essa questão as epistemologias voltadas para a dimensão das sexualidades e, mais precisamente, as epistemologias relacionadas ao feminismo lesbiano negro interseccional?

A sexualidade da mulher foi (e continua sendo) um tabu. Expressá-la ainda representa, na nossa contemporaneidade, fazer parte de um grupo em que, nós mulheres lesbianas, por estarmos fora da ordem heteronormativa, somos consideradas com certa frequência aberrações e por essa razão não estamos legitimadas a falar sobre esse tema.

Diante do contexto da heteronormatividade, em que a norma impõe a heterossexualidade e considera inferiores as demais orientações sexuais, uma mulher negra e lesbiana, excluída e discriminada por não se encaixar nesse padrão, torna-se vulnerável a todo tipo de violência. Por tudo isso, é urgente a existência de novos olhares epistêmicos que venham a desestabilizar a (i)lógica perversa da heteronormatividade. Dessa forma, o objetivo deste artigo é apresentar uma reflexão acerca das epistemologias que tratam sobre a sexualidade das mulheres negras lesbianas inseridas no contexto do heteropatriarcado. Na perspectiva do feminismo negro interseccional, a intenção é contribuir para a visibilidade das mulheres lesbianas negras. $\mathrm{O}$ ato de visibilizar consiste uma estratégia importante de enfrentamento dos estigmas e, ao mesmo tempo, de resistência, "onde há relações de poder, há resistências" (FOUCAULT, 2005). Dito isso, sigo a análise discursiva com base na perspectiva epistemológica pós-estruturalista, dialogando com algumas teóricas feministas lesbianas negras entre outras/os. 


\section{Procedimentos metodológicos}

O presente artigo teórico faz parte de uma pesquisa de doutorado em andamento. Neste primeiro momento, o objetivo central é, por meio de uma revisão de literatura, fazer uma reflexão acerca das epistemologias que tratam da questão das sexualidades dissidentes, mais precisamente sobre a sexualidade de mulheres negras lesbianas inseridas no contexto do heteropatriarcado.

À luz do feminismo negro interseccional, o propósito é, mediante uma discussão sobre o tema proposto, contribuir para um aporte epistemológico em que as mulheres lesbianas negras, com o auxilio de contribuições teóricas de algumas feministas lesbianas negras, sejam colocadas no centro da discussão e ocupem seu lugar de fato e de direito.

\section{Lugar de fala: falar por ou falar com?}

Uma mulher lesbiana branca está autorizada a falar por uma mulher lesbiana negra? Nesse sentido, estar no lugar de fala na condição de mulher lesbiana branca, por si só, é suficiente para que se possa falar por uma mulher lesbiana negra? Essas são algumas perguntas que precisam de uma atenção especial, haja vista a não perpetuação de privilégios por parte da branquitude que se pode reverberar em preconceito racial, discriminação racial, racismo, situações em que mulheres lesbianas negras serão excluídas e silenciadas.

Em um contexto maior, em se tratando da temática do racismo, é necessário abrir um espaço para conceituar e contextualizar a branquitude. Os estudos sobre esse tema explodiram no Brasil nas últimas décadas quando se incluiu o debate sobre a identidade racial branca. No centro da discussão sobre racismo, até então, não era comum a pessoa opressora ser tratada como centro da questão, pois "não se trata, portanto, de teoria sobre relações raciais, trata-se de uma abordagem unilateral, feita muitas vezes por prestigiados pesquisadores brancos preocupados em analisar o 'problema do negro'" (CARDOSO, 2010).

O termo branquitude, utilizado para referir-se a uma situação de privilégio das pessoas brancas, contribui para deslocar o foco da atenção da pessoa oprimida, a mulher negra, o homem negro para a pessoa opressora, a mulher branca e o homem branco. Piza (2005) sugere que, além de movimento de negação da supremacia branca, enquanto expressão de humanidade, a branquitude deve ser pensada como uma identidade branca negativa.

Possuir características fenotípicas de uma pessoa branca foi durante muito tempo um padrão desejado. Esse modelo representou o verdadeiro ser humano, o ser humano ideal e, dessa forma, legitimou-se uma possibilidade de vida fundada em privilégios. Nessa realidade, mantêm-se sociedades hierarquizadas, em que as pessoas negras ainda são discriminadas e oprimidas. 
Todas as pessoas fazem uso de um lugar de fala. Uma mulher negra e lesbiana pode vivenciar ainda condições de subalternidade, a qual pode estar associada "às camadas mais baixas da sociedade constituídas pelos modos específicos de exclusão dos mercados, da representação política e legal, e da possibilidade de se tornarem membros plenos no estrato social dominante" (SPIVAK, 2010: p. 12). Falar a partir de lugares é também romper com a lógica de que somente os subalternos falem de suas localizações, fazendo com que aqueles inseridos na norma hegemônica sequer se pensem (RIBEIRO, 2017).

Pensar em lugar de fala é pensar nos lugares de onde se fala, em localização social e considerar, sobretudo, as vozes silenciadas e invisibilizadas. O fundamental é que as pessoas privilegiadas em termos de lócus social consigam enxergar as hierarquias produzidas nesse lugar e entender que este impacta diretamente na constituição dos lugares de grupos subalternizados (RIBEIRO, 2017).

Para uma mulher que, na perspectiva histórica de uma sociedade racista, se constituiu de privilégios por ser branca, a tomada de consciência deste estado deve vir acompanhada do processo permanente da escuta e, sobretudo, de um olhar crítico para tudo o que acontece a nossa volta, de modo que práticas racistas não sejam corroboradas pelo silêncio ou pela falta de escuta. Nessa direção, Cardoso, (2010) chama atenção para "a branquitude crítica que desaprova o racismo "publicamente", em detrimento da branquitude acrítica que não desaprova o racismo e sustenta que ser branco é uma condição especial, uma hierarquia obviamente superior a todos não brancos". Dito de outra forma, "não se pode falar pelo subalterno, mas pode-se trabalhar 'contra' a subalternidade, criando espaços nos quais o subalterno possa se articular e, como consequência, possa também ser ouvido" (SPIVAK, 2010: p. 14).

Então, em um permanente estado de atenção e, mormente, com o reconhecimento acerca dos privilégios históricos que envolvem a questão da branquitude, é possível chegar a uma escuta com relação a essas mulheres inseridas em um contexto de opressão, de violência ou de subalternidade e, assim, o "falar com" prevalecerá sobre o "falar por".

\subsection{O heteropatriarcado: a marca da exclusão e da violência}

Diante da dimensão e do impacto nas sociedades, esse tema precisa ser incansavelmente discutido e enfrentado por todas/os, dentro e fora da academia, pois "a fundação do patriarcado é a opressão das mulheres. O cimento da sua fundação é a socialização dos homens para odiarem as mulheres" (HOOKS, 2014 p. 74). Assim, a vivência das mulheres, sobretudo a das mulheres negras torna-se um permanente desafio no que diz respeito ao enfrentamento das mais variadas formas de violências, exclusões e silenciamentos gerados pelo heteropatriarcado.

Apesar de constituir uma estrutura milenar presente desde os tempos mais remotos da humanidade, o heteropatriarcado encontra sempre uma forma de se reinventar e marcar presença na nossa 
contemporaneidade, com a garantia de direitos e liberdades para homens, em detrimento dos direitos e liberdades das mulheres. É comum uma pessoa que se autoidentifica gênero masculino passar a desfrutar dos privilégios por estar neste gênero, o fato é que "desde cedo meninos negros aprendem que por terem nascido no gênero masculino possuem um estatuto superior ao das mulheres" (HOOKS, 2014, p.74).

Há um abismo descomunal entre o universo composto pelas mulheres e o composto pelos homens. Isso nos leva a pensar quanto tudo, ou quase tudo, que vivemos, em termos de desigualdade e opressão direcionadas a nós mulheres, está de forma direta ou indireta associada ao heteropatriarcado presente nas instituições e organizações de modo geral, nas ciências, nas religiões e nas leis. Hooks (2014) chama atenção para o combate ao racismo, uma luta em que as próprias mulheres negras foram oprimidas pelo heteropatriacado do homem negro. Na batalha contra o racismo, o protagonismo do homem negro aconteceu como consequência de um intenso sexismo que exigiu um papel de total subserviência da mulher negra, apesar de toda a sua história de participação ativa nesse embate. Os homens negros mostraram um grande desinteresse em lutar contra o sexismo e, dessa forma, perpetuaram e fortaleceram opressões e violências direcionadas às mulheres negras.

As diversas opressões vivenciadas pelas mulheres, sobretudo as mulheres negras, constituíram uma norma, presente nos diversos campos dos saberes e fazeres. No entanto, isso não foi determinante a ponto de elas desistirem de lutar ou de estar presentes nas diferentes frentes de batalha, nas lideranças de grupos ativistas, muitas vezes colocando em risco a sua integridade física e/ou psíquica em busca de uma sociedade menos desigual em que tivessem voz própria e condições para traçar o rumo das suas vidas.

A estrutura opressora e excludente do patriarcado é tão marcante e se impõe de tal forma que se torna quase impossível operar fora dessa lógica patriarcal. Saffioti (2015) adverte para um "esquema patriarcal de pensamento e nos diz que "colocar o nome da dominação masculina - patriarcado - na sombra, significa operar segundo a ideologia patriarcal, que torna natural essa dominação-exploração”. Mulheres e homens são constituídos nesse sistema e não é surpreendente ou mesmo incomum percebermos o vasto campo de dominação masculina. Sobre isso, Hooks (2014) declara:

a atenção que a família nuclear patriarcal faz todos os seus membros dependerem do homem (pai-marido). É nesta atmosfera opressiva que crescemos e somos extremamente sensitivos a esta hierarquia de poder mesmo quando crianças. Nós percebemos, mais do que os adultos pensam, que o nosso pai (e a sociedade na sua imagem, do policial, ao médico, ao presidente) é poderoso, e que a nossa mãe não tem poder. Ela tem que ter esquemas e manipular através da simpatia para ter o que ela pretende. (p. 74). 


\subsection{O heteropatriarcado e a sexualidade da mulher lesbiana negra}

A temática sobre sexualidades vem sendo muito discutida no Brasil nas últimas décadas e, como questão acadêmica, passa a se constituir mais visivelmente a partir da década de 1980, ainda no século XX, com o apoio das teorizações de Michel Foucault (LOURO, 2008). No entanto, apesar do perceptível crescimento do interesse pelo tema, esse campo carece de trabalhos acadêmicos (e afins) que abordem especificamente sobre as mulheres lesbianas, mormente as lesbianas negras, suas angústias, desafios, alegrias, dores e amores. Existe uma robusta bibliografia que trata das questões da identidade gay branca e, mais recentemente, das transidentidades.

A escassa visibilidade das lesbianas, em especial das lesbianas negras, é algo que contribui para um cenário de mais estigmas e violências. Basta uma busca rápida pelos principais sites e repositórios sobre o assunto e/ou uma procura rápida pelas principais livrarias, feiras de livros, inclusive em congressos especializados em gênero e sexualidade, para comprovar esse deserto de trabalhos em torno das lesbianidades.

No campo das sexualidades, não por acaso, os medos e inseguranças ainda estão presentes na contemporaneidade. Em pleno século XXI, esse tema está cercado de tabus, preconceitos e opressões. No mundo patriarcal, os valores religiosos e morais definem a visão do que é humano e o amor e o sexo entre mulheres representam ameaça de perda de poder por quem domina (NAVARRO-SWAIN, 2004). Nessa direção, Clarke (1998) destaca o culto feito aos patriarcas do par homem-mulher, considerado algo natural, pensado na manutenção da heterossexualidade da mesma forma que o culto da superioridade caucasiana para justificar a escravidão dos povos de África.

Uma coisa interessante a ser observada nisso tudo é o fato de que um dos elementos nucleares do patriarcado se lastreia exatamente no controle da sexualidade feminina, para assegurar a fidelidade da esposa a seu marido (SAFFIOTI, 2015). Dessa forma, o homem consegue assegurar seu domínio sobre ela. Para Rich (2010), a heterossexualidade compulsória, instituição política a serviço da soberania masculina, toma o poder das mulheres e convence-as de que o casamento e a heterossexualidade são inevitáveis.

Os medos e inseguranças, no que diz respeito à vivência e expressão das sexualidades dissidentes, ainda estão presentes na contemporaneidade. $\mathrm{O}$ controle da sexualidade da mulher é exercido por uma incansável vigilância e, em pleno século XXI, constitui um tema cercado de tabus, preconceitos e opressões. As mulheres lesbianas, as mulheres negras lesbianas, apesar da desvalorização e invisibilização a que estão submetidas, desafiam a ordem do heteropatriarcado pela sua própria existência.

Pois bem, ao longo da história, a invisibilização, a discriminação e o apagamento das mulheres lesbianas têm sido uma prática recorrente. As mulheres lesbianas negras não escapam à regra e se tornam integrantes silenciadas da política do esquecimento (NAVARRO-SWAIN, 2004). Para Saunders (2017, p. 
107), "o apagamento da lésbica é central para a opressão das mulheres heterossexuais; um processo que reforça a heterossexualidade é uma instituição política que desacredita as mulheres". Em todos esses silêncios está contido o medo da censura, do julgamento, do desprezo, do aniquilamento. Em outras palavras, está presente o temor de uma visibilidade sem a qual não se pode viver verdadeiramente (LORDE, 2009).

\subsection{Em direção a um aporte epistemológico das lesbo-feministas-pretas}

A relação entre lesbianidade e feminismo tem sido marcada por conflitos e tensões, presentes tanto no campo epistêmico, quanto no campo político. Ao longo da história, a palavra lésbica está envolta de representações negativas e "existe um profundo mal-estar social em torno da lesbianidade, seja para negá-la enquanto prática corrente, seja para desqualificá-la enquanto mutilação do ser mulher" (SWAIN, 2014).

O ser humano é diverso e múltiplo com toda sua riqueza composta pelas singularidades e especificidades. Contudo, de acordo com Saunders (2017):

\footnotetext{
$\mathrm{Na}$ epistemologia e ontologia ocidentais, é o corpo lésbico negro, o pervertido feminino negro, e no caso do Brasil, a bruxa negra, que serve de sustentação para as definições do "não-humano", enquanto o cisgênero, masculino, branco, rico, heterossexual, cristão e burguês (também conhecido como Homem) continua a servir como sustentação para o "humano", um processo enraizado na América colonial (p. 107).
}

O movimento feminista, durante muito tempo, recusou-se a olhar para as especificidades e singularidades que envolvem a categoria mulher. Ao contrário, tratou essa categoria como universal e homogênea, assentando-se, assim, em uma base predominantemente heterossexista e racista, em que as mulheres lesbianas e mulheres negras lesbianas não eram contempladas por essa agenda. Foi preciso coragem e força revolucionária das mulheres lesbianas e das mulheres lesbianas negras para questionar seu espaço, no intuito de mostrar que, para além da opressão histórica que atingia a todas as mulheres, havia as opressões de raça, gênero, sexualidade, entre outras.

Logo, o feminismo lesbiano percebeu que tinha outras demandas, até então desprezadas pelo feminismo heterossexista. Quando surgiram os primeiros grandes coletivos gays mistos, o espaço de poder das mulheres era muito limitado e ainda estava subordinado ao poder dos homens gays. Tal fato motivou a saída de muitas delas desses coletivos, criando, assim, outros coletivos que buscassem atender as suas expectativas e especificidades. Entretanto, ao se separarem desses coletivos, nunca deixaram de nutrir as 
suas fontes. Um passou a nutrir-se do outro, haja vista o combate ao heteropatriarcado representar uma pauta comum inclusive nos dias atuais.

Historicamente, as mulheres têm sido alvo de formas de violências que ratificam o poder dos homens sobre elas, inclusive no campo da sexualidade, e isso pode ser comprovado pela prática da clitoridectomia e infibulação, bem como por outros tipos de punição, inclusive a morte, em razão da sexualidade lesbiana (RICH, 2010). Essas mulheres trazem consigo histórias de opressões e violências que se diferem entre elas e variam em níveis e intensidades, com impacto direto nas histórias de vidas pessoais. No caso específico das mulheres negras e lesbianas, é imprescindível um olhar para o triplo viés dessas opressões: gênero, raça e sexualidade. São categorias que se interseccionam e se potencializam, não havendo hierarquização entre elas (LORDE, 2009).

Diante de um contexto da heteronormatividade, em que a heterossexualidade marca as demais orientações sexuais como inferiores, para uma mulher negra e lesbiana, julgada um ser inferior por não se encaixar nessa norma, e, portanto, vulnerável a todo tipo de violências, os caminhos possíveis a seguir para sobreviver podem ser: esconder-se no "armário", ou, melhor dito, manter-se invisibilizada e/ou, ainda, adiar a vivência e expressão de sua sexualidade, o que pode significar uma ameaça permanente a sua integridade psíquica. Para Saunders (2017, p. 107), “o apagamento da lésbica é central para a opressão das mulheres heterossexuais; um processo que reforça a heterossexualidade é uma instituição política que desacredita as mulheres".

Diante dessa problemática exposta, em que estar fora da norma imposta representa ameaça constante, podemos imaginar como deve ser desafiador para as mulheres negras lesbianas viverem e expressarem sua sexualidade, visto que a lesbofobia enraizada na sociedade racista brasileira e na própria comunidade negra muitas vezes a rechaça por sua homossexualidade.

A questão da invisibilidade lesbiana é um problema constante na vida de muitas mulheres e geradora de violências, sejam simbólicas ou ostensivas, sinalizando a negação de existência pública (SIQUEIRA E ANDRADE, 2012). Se considerarmos que a sexualidade é um importante componente da personalidade de uma pessoa, seria um equívoco imaginarmos uma coisa separada da outra ou ainda associarmos a sexualidade a uma questão exclusivamente de foro íntimo. Podemos nos referir a ela como uma questão pública e organizacional, devido ao fato de ela delinear o comportamento de homens e mulheres, construir expectativas, definir posições, acesso a cargos, bem como privilégios (IRIGARAY, 2011).

No Brasil, este é um momento violento para se assumir abertamente uma identidade lesbiana, particularmente uma identidade lesbiana negra - econômica, política e fisicamente (SAUNDERS, 2017). Com isso, o acesso ao mercado de trabalho não ocorre de forma igualitária e inclusiva e está marcado por muitas barreiras e restrições (VALENTE, 2000). Nesse contexto, tudo isso dificulta o seu 
empoderamento, quando se trata de desafio à ideologia patriarcal, ou seja, um processo de superação da desigualdade de gênero (LEÓN, 2000).

Então, a luta por uma existência lesbiana negra passa pelo triplo viés das opressões produzidas e reiteradas cotidianamente por um heteropatriarcado pulsante, marcadas pelo gênero, raça e sexualidade, categorias que se interseccionam e se potencializam. Para isso, os estudos das teóricas feministas lesbianas negras têm um papel fundamental para colocar em pauta essa questão muito oportuna nos dias sombrios que estamos vivenciando. O silêncio sobre essa temática representa mais uma violência.

\section{Considerações finais}

O presente trabalho teve como proposta fazer uma revisão de literatura acerca das epistemologias sobre as lesbianidades de mulheres negras inseridas no contexto do heteropatriarcado, à luz dos estudos de teóricas feministas negras lesbianas que, por muito tempo, foram discriminadas e excluídas dos coletivos formados por gays e pelos próprios movimentos feministas, os quais se recusaram a olhar para as especificidades e singularidades da categoria mulher. Durante muito tempo essa categoria foi tratada como universal e homogênea, assentando-se, assim, em uma base predominantemente heterossexista e racista, em que as mulheres lesbianas, mulheres negras e mulheres negras lesbianas não eram contempladas por essa agenda. Foi preciso, então, coragem e força revolucionária das mulheres lesbianas negras e das mulheres lesbianas, de modo geral, para questionar seu espaço, no intuito de mostrar que, para além da opressão histórica que atingia a todas as mulheres, fruto de um heteropatriarcado vigente nos dias atuais, havia as opressões de raça e sexualidade, as quais deveriam ser analisadas em uma perspectiva interseccional.

Pois bem, viver fora da norma imposta representa ameaça constante à vida de uma mulher lesbiana. Nesse contexto, o heteropatriarcado se mostra um campo propício para estudar esse tema, uma vez que sua base se sustenta em práticas racistas e heterossexistas. Então, este trabalho propõe um olhar que passa pelo triplo viés, mulher, raça e lesbianidade, categorias que se interseccionam e se potencializam.

Além do supracitado, pretendemos dar os primeiros passos, com o propósito de contribuir para uma epistemologia que problematize, questione e subverta o que é considerado único, certo e determinado, apontando caminhos capazes de romper e desmistificar as formas fossilizadas e preconceituosas de tratar a sexualidade da mulher negra lesbiana. Dessa forma, é possível colaborar para uma maior visibilidade, haja vista serem muito estigmatizadas e desrespeitadas. 


\section{Referências}

CARDOSO, Lourenço. Branquitude acrítica e crítica: A supremacia racial e o branco antiracista. Rev.latinoam.cienc.soc.niñez juv, Manizales , v. 8, n. 1, p. 607-630, Jan. 2010 . Available from <http://www.scielo.org.co/scielo.php?script=sci_arttext\&pid=S1692715X2010000100028\&lng=en\&nrm=iso $>$. access on 07 Aug. 2019.

CLARKE, C. Lesbianismo como ato de resistência. In: Esta puente, mi espalda: Vozes de las mujeres terceiro-mundista en los Estados Unidos. Trad. Cherríe Moraga e Ana Castillo. Ed.1988. São Francisco-USA: ISM Press, 1988.

FOUCAUlT, M. História da Sexualidade. A vontade de saber. Trad. Maria Thereza da Costa Albuquerque e J.A. Guilhon Albuquerque. São Paulo graal 2005. V. 1

HOOKS, B.. Não sou eu uma mulher. Mulheres negras e feminismo. Janeiro, 2014.

IRIGARAY, A. Orientação sexual e trabalho. GV- executivo. v. 10, n. 2, 2011.

LEÓN, M. EMPODERAMIENTO: RELACIONES DE LAS MUJERES COM EL PODER. Revista Estudos Feministas, Florianópolis, v. 8, n. 2, p. 191, jan. 2000. ISSN 1806-9584. Disponível em: $<$ https://periodicos.ufsc.br/index.php/ref/article/view/11935>. Acesso em: 17 out. 2018.

LORDE, A. Herética Difusão lesbofeminista independente. Textos escolhidos de Audre Lord: Não há hierarquias entre as opressões Retirado e traduzido de "I Am Your Sister - COLLECTED AND UNPUBLISHED WRITINGS OF AUDRE LORDE”, Oxford University Press, 2009.

LOURO, G. Um corpo estranho - ensaios sobre sexualidades e teorias queer- Belo Horizonte: Autêntica, 2008.

MESSEDER, S. A.. A construção do conhecimento científico blasfêmico ou para além disso nos estudos de sexualidades e gênero. In: IRINEU, B. A. (Org.). Diversidades e políticas da diferença: intervenções, experiências e aprendizagens em sexualidade, gênero e raça. 1ed.Tocantins: EDUFT, 2016, v. 01, p. 06-17.

NAVARRO-SWAIN, T. O que é lesbianismo. São Paulo: Brasiliense, 2004. 
PIZA, Edith. Adolescência e racismo: uma breve reflexão.. In: SIMPOSIO INTERNACIONAL DO ADOLESCENTE, 1., 2005, São Paulo. Proceedings online... Available from: $<$ http:/ /www.proceedings.scielo.br/scielo.php?script=sci_arttext\&pid=MSC0000000082005000100022\& lng $=$ en\&nrm $=$ abn $>$. Acess on: 07 Aug. 2019.

RIBEIRO, Djamila. O que é lugar de fala? Belo Horizonte: Letramento: Justificando, 2017.

RICH, A. Heterossexualidade compulsória e existência lésbica. Bagoas: estudos gays: gêneros e sexualidades. Natal, 4 (5), jan./jun, pp. 23-24, 2010.

SAFFIOTI, H. Gênero patriarcado violência. Ed. 2. São Paulo: Expressão popular/Fundação Perseu Abramo, 2015.

SAUNDERS, T. L. Epistemologia negra sapatão como vetor de uma práxis humana libertária. Periodicus ISSN: 2358-0844 n. 7, v. 1 maio-out. 2017 p. 102-116.

SEDGWICK, E. K. A epistemologia do armário. Cad. Pagu, Campinas, n. 28, p. 19-54, June 2007. Available from <http://www.scielo.br/scielo.php?script=sci_arttext\&pid=S010483332007000100003\&lng=en\&nrm=iso $>$. access on 29 June 2017. http://dx.doi.org/10.1590/S010483332007000100003.

SPIVAK, Gayatri Chacravorty. Pode um subalterno falar?. Belo Horizonte: Editora UFMG (2010[1985]) VALENTE, Virginia Vargas. UNA REFLEXION FEMINISTA DE LA CIUDADANÍA. Revista Estudos Feministas, Florianópolis, v. 8, n. 2, p. 170, jan. 2000. ISSN 1806-9584. Disponível em:

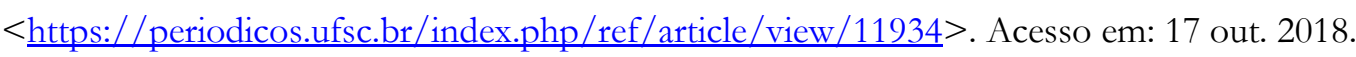

